\title{
Distribuição da lateral /// em coda no português santomense
}

DOI: http://dx.doi.org/10.21165/el.v49i2.2490

\author{
Amanda Macedo Balduino' \\ Nancy Mendes Torres Vieira²
}

\section{Resumo}

O português santomense (PST) é uma das variedades do português faladas em São Tomé e Príncipe e compartilha características estruturais com o português brasileiro (PB), com o português europeu (PE), além de apresentar características intrínsecas, evidenciadas pela distribuição da lateral em coda que, a exemplo do PB e do PE, pode ser produzida como [t] ou [w]. Este artigo tem como objetivo descrever a distribuição de /l/ em coda no PST, bem como analisar os processos de velarização [t] e vocalização [w] nesta variedade. Foi constatada a produção de [t] em 49,87\% dos dados e de [w] em 19,1\%, sendo a forma vocalizada favorecida quando a vogal anterior era [dorsal].

Palavras-chave: lateral; distribuição da coda; português santomense; velarização; vocalização.

\footnotetext{
1 Universidade de São Paulo (USP), São Paulo, São Paulo, Brasil; amanda.m_b@hotmail.com; https://orcid.org/0000-0002-1062-973X

2 Universidade de São Paulo (USP), São Paulo, São Paulo, Brasil; nancy.vieira@usp.br; https://orcid.org/0000-0002-7291-9759
} 


\title{
Distribution of the lateral /// in coda in Santomean Portuguese
}

\begin{abstract}
The Santomean Portuguese (PST) is one of the varieties of Portuguese spoken in São Tomé and Príncipe and shares structural characteristics with Brazilian Portuguese (BP) and European Portuguese (EP), besides presenting intrinsic characteristics evidenced by the distribution of the lateral in coda which, just as in BP and EP, can be produced as [t] or [w]. This study aims to describe the /// distribution in coda in PST, as well as to analyze the processes of velarization [t] and vocalization [w] in this variety. It was noticed that [t] was produced in $49,87 \%$ of the corpus and [w] occurred in $19,1 \%$ of the data, being the vocalized form favored when the preceding vowel was [dorsal].
\end{abstract}

Keywords: lateral; coda distribution; Santomean Portuguese; velarization; vocalization.

\section{Introdução}

As variedades do português faladas na África constituem um amplo campo de estudos, uma vez que os trabalhos dedicados à sua descrição e análise são esparsos. Conforme Brandão et al. (2017), não há, ainda, trabalhos suficientes que determinem, sincronicamente, as normas que caracterizam tais variedades, sobretudo, porque estas apresentam caráter emergente. Em relação ao Português Vernacular Santomense (PST), o cenário não é muito distinto, pois os estudos são poucos e estão concentrados na última década (cf. FIGUEIREDO, 2010; GONÇALVES, 2010; CHRISTOFOLETTI, 2013; BRANDÃO et al., 2017; BOUCHARD, 2017; BRAGA, 2018; BALDUINO, 2018, ARAUJO; BALDUINO, 2019; BALDUINO, 2019).

Em geral, os países africanos que possuem o português como língua oficial apresentam ecologia linguística complexa circunscrita a um quadro linguístico diversificado, caracterizado pela coexistência de diferentes línguas. Em São Tomé e Príncipe (STP), país da costa oeste africana, o português, língua oficial desde a constituição de 1975, apesar de conviver com línguas autóctones, como o santome e o angolar, é mantido como língua de prestígio, configurando a língua mais empregada do arquipélago. Assim, distintamente de países como Moçambique, em que apenas 6,5\% dos cerca de 20 milhões de habitantes possuem o português como língua materna (L1) (GONÇALVES, 2010), em STP, cerca de 98,2\% da população santomense emprega o português como L1 (cf. INE, 2011).

Em STP, a norma linguística difundida na escola e na mídia é o português europeu, o qual difere em diversos aspectos estruturais do PST (cf. BALDUINO, 2018). Diante desse fato, temos como objetivo, neste artigo, descrever e analisar a distribuição da lateral /// na coda silábica do PST, focando na possibilidade de ocorrência de processos fonológicos 
como a velarização e a vocalização, os quais podem ser atestados no português europeu (PE) e no português brasileiro (PB). Esse estudo, embora preliminar, é justificado, assim, por contribuir com a descrição e análise fonológica de uma variedade do português pouco descrita, ampliando a literatura voltada a esse tema e, consequentemente, a documentação linguística do PST.

\section{A velarização e a vocalização da lateral em coda: português brasileiro e português europeu}

Mateus e D'Andrade (2000), com base na norma lisboeta do português, assume que a forma mais comum da lateral em coda, no PE, é a velar, sendo a lateral realizada em uma região linguo-velar e produzida como [t] nesta posição. Para Mateus e Rodrigues (2003) e Brandão et al. (2003), a manutenção da lateral em coda indica a tendência do PE em manter um padrão CVC, não favorecendo processos de enfraquecimento e apagamento da coda consonantal.

No PB, de outro modo, /I/ pode ser realizado como [t] ou [w] em coda, a depender do dialeto empregado (cf. CÂMARA JR., 1970), sendo que, de acordo com Quednau (1993), tais regras são empregadas por indivíduos distintos. De acordo com tais autores, o emprego de [t] ou [w] é descrito por variação diatópica, sendo que o falante empregará [t] ou [w] conforme a norma vigente em sua comunidade de fala. A possibilidade de vocalização da lateral, no PB, de acordo com Brandão et al. (2003) configura um indício de que, em tal variedade, o padrão silábico preferido é $C V$, uma vez que a vocalização é caracterizada como um fenômeno de enfraquecimento, o qual se encaminha para o apagamento, como detectado em outras consoantes licenciadas em coda no PB (cf. BRANDÃO et al., 2003).

De modo geral, a coda é um constituinte crucial para a descrição fonológica do português, bem como para a discussão de processos que apresentam tal constituinte como domínio. Tendo como foco o comportamento de /// na coda, compreendemos que o PB e o PE apresentam um comportamento distinto para a distribuição fonética da lateral, variando quanto à produção de [t] e [w]. Isso posto, nosso objetivo é descrever o preenchimento atribuído à coda lateral, bem como discutir a possibilidade de velarização e vocalização de /I/ no PST.

\section{Corpus e Metodologia}

Esta pesquisa é pautada em 744 ocorrências, ou 200 itens lexicais, que continham a lateral /l/ em posição de coda no PST. Tais ocorrências foram retiradas de um corpus coletado na cidade de São Tomé, o qual é constituído por entrevistas sociolinguísticas gravadas in loco em 2016 e 2019. Neste estudo, trabalhamos com 10 entrevistas com duração de aproximadamente 60 minutos cada uma, descartando, no entanto, os 15 primeiros 
minutos de tais gravações de modo a trabalharmos com uma produção mais próxima à fala vernacular dos informantes. Como o propósito deste artigo é propor uma descrição preliminar do comportamento da lateral em coda consonantal no PST, examinamos fenômenos como a vocalização, a velarização e o apagamento de /l/, porém não nos dedicamos ao estabelecimento estatístico de variáveis independentes que favorecem tais fenômenos.

Uma análise sociolinguística está além do escopo deste trabalho, todavia, ressaltamos os prováveis efeitos que variáveis como o gênero, a escolaridade e, principalmente, a faixa etária podem exercer na aplicação de tais processos, posto que o PST é uma variedade que apresenta algumas mudanças linguísticas em curso (cf. BOUCHARD, 2017). Embora o objetivo desta análise não recaia sobre esses fatores, reconhecendo sua possível relevância, uniformizamos a escolarização em dois conjuntos, a saber: média (de 4 a 9 anos) e alta (acima de 9 anos), como será discutido adiante, e investigamos os dados considerando as diferentes faixas etárias, observando se, em termos percentuais, são identificadas tendências que sugiram a relevância desse fator que deve, posteriormente, ser compreendido mediante estatística analítica ${ }^{3}$.

Para exame dos dados, elegemos até seis ocorrências de cada palavra, ampliando o corpus de forma a operarmos com uma amostra mais variada de palavras. Isso posto, as 744 ocorrências eleitas foram submetidas a uma análise acústica, para, assim, confirmarmos foneticamente os fenômenos de vocalização, velarização e apagamento da lateral nos dados. Para tanto, nos valemos do Praat ${ }^{4}$, pelo qual observamos, com base em alguns critérios fonológicos, a tonicidade da palavra, a qualidade dos segmentos precedentes e a distribuição posicional da lateral dentro do item alvo, a presença de uma lateral velar, vocalizada, ou mesmo a ausência segmental, aqui representada como $\emptyset$.

Acusticamente, tanto [l] quanto [t] são demarcadas por uma estrutura formântica visível, porém, menos intensa em relação aos formantes vocálicos, mudando abruptamente de intensidade entre o final da lateral e o início de uma vogal vizinha. De acordo com Ladefoged e Johnson (2011), a lateral [1], além de uma estrutura formântica menos intensa, no geral, apresenta formantes centralizados com aproximadamente $250 \mathrm{~Hz}$ (F1) e $1100 \mathrm{~Hz}(\mathrm{~F} 2)$.

3 Como não trabalhamos, diretamente, com a duração dos segmentos, não homogeneizamos o gênero dos informantes. É preciso ressaltar, desse modo, que podem haver fenômenos fonéticos subjacentes à fala de homens e mulheres (cf. POST, 2019) que interfiram nos resultados.

4 Praat (BOERSMA; WEENINK, 2015) - Software utilizado para análise e síntese de fala, pelo qual é possível acessar informações acústicas do segmento, como a duração, o formato de onda, o espectrograma e, no caso deste trabalho, sua ausência física. 
Um segmento foi classificado como velar [t] quando o primeiro (F1) e o segundo formantes (F2), nítidos por conta da característica soante da lateral, estão próximos (cf. figura 1). Em geral, na produção de [t], segmento realizado em uma região línguo-velar, F1 tenderá a ser alto e mais próximo a F2, ao passo que, se a consoante for realizada em uma região línguo-alveolar [I], F1 será menor (cf. BROD, 2014).

Figura 1. Produção de [t] em falta ['fałte]

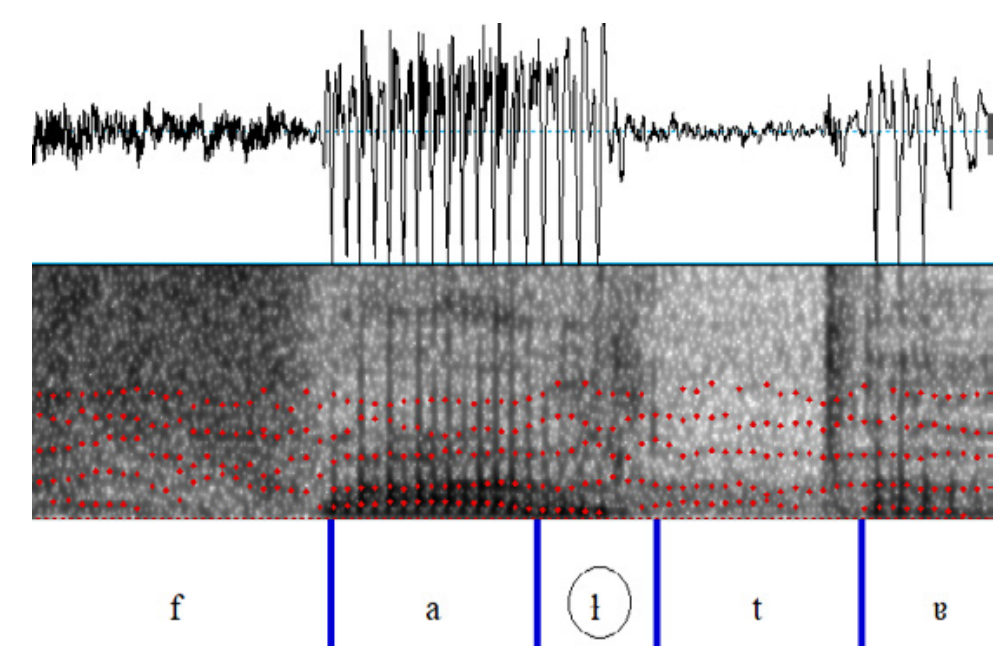

Fonte: Elaboração própria

De outro modo, o segmento vocalizado [w], a exemplo das vogais, apresenta estrutura formântica intensa, possui valores mais baixos para os três primeiros formantes, uma trajetória de formantes próxima daquela encontrada em ditongos decrescentes e menor duração do segmento vocalizado em relação às realizações de sons laterais (cf. BROD, 2014, p. 119) (cf. figura 2). 
Figura 2. Produção de [w] em alguma [a'nєw]
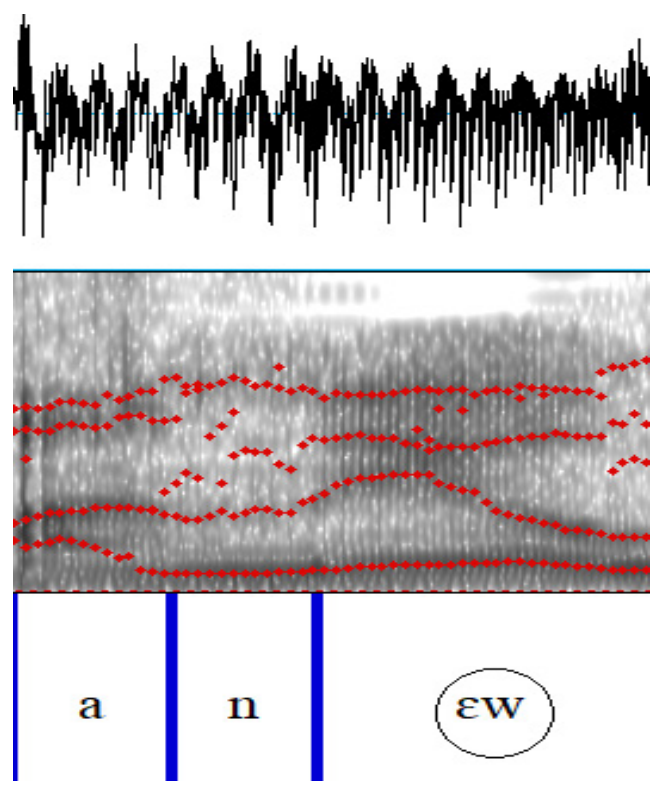

Fonte: Elaboração própria

Por fim, a ausência acústica de reflexos fonéticos que indiquem a presença de um segmento velarizado ou vocalizado atestou o apagamento segmental de /l/ (cf. figura 3).

Figura 3. Apagamento de /// em maltrata [ma'tвate]
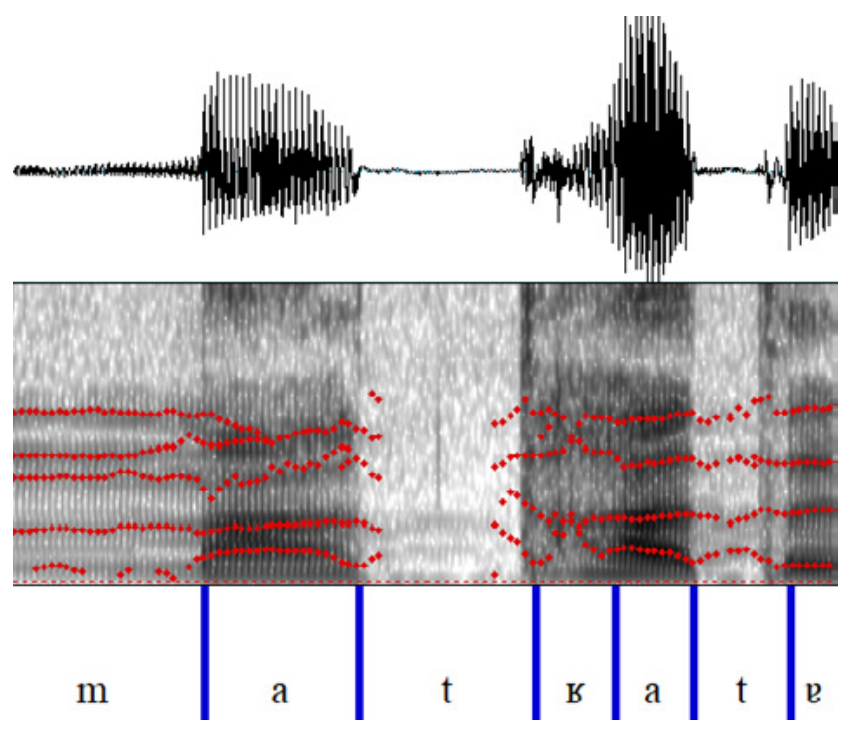

Fonte: Elaboração própria 
O exame das ocorrências foi realizado tendo em vista alguns critérios fonológicos que, hipoteticamente, podem corresponder a gatilhos para realização da velarização, vocalização e/ou apagamento. Dessa forma, analisamos (i) a tonicidade da sílaba que contém o segmento; (ii) a posição do segmento dentro da palavra, investigando dados em que /I/ estava em posição interna à palavra e dados nos quais a lateral estava em fronteira de palavra; e, por fım, (iii) a distribuição de /// em coda de acordo com o contexto fônico precedente.

A escolha dos informantes, além do sexo e da faixa etária, estabelecida em até 29 anos e a partir de 30 anos, considerou a naturalidade, a língua materna e a escolaridade. Dessa forma, todos os informantes eram naturais da Ilha de São Tomé, tinham o português como língua materna e apresentavam, pelo menos, escolarização média (4 - 9 anos) ou alta (acima de 9 anos), como elucidado pelo quadro $1^{5 .}$

Quadro 1. Informantes do PST

\begin{tabular}{|c|c|c|c|}
\hline Sujeito & Idade & Sexo & Escolaridade \\
\hline 1 & 18 & Feminino & Alta \\
\hline 2 & 19 & Feminino & Alta \\
\hline 3 & 19 & Masculino & Alta \\
\hline 4 & 22 & Masculino & Alta \\
\hline 5 & 33 & Feminino & Alta \\
\hline 6 & 33 & Feminino & Média \\
\hline 7 & 33 & Feminino & Alta \\
\hline 8 & 18 & Masculino & Alta \\
\hline 9 & 43 & Masculino & Média \\
\hline 10 & 52 & Masculino & Alta \\
\hline
\end{tabular}

Fonte: Elaboração própria

Estabelecidos os passos metodológicos, na seção a seguir, discutimos a distribuição da lateral /// em coda no PST, tratando, separadamente, cada uma das realizações fonéticas identificadas.

5 A escolarização obrigatória, em São Tomé e Príncipe, equivale a 6 anos. Dessa forma, adultos que têm, pelo menos, quatro anos de escolarização, já são considerados bem escolarizados em relação à realidade educacional do país. 


\section{Velarização e Vocalização de /I/ em coda no português vernacular santomense}

Nesta seção, examinaremos dados em que /// estava em coda, enquanto a lateral velar [t] foi realizada em $49,87 \%$ do corpus, sendo identificada em 371 ocorrências, a forma vocalizada [w] foi produzida em 19,09\% dos dados, o que equivale a 142 ocorrências. 0 apagamento da lateral, por sua vez, ocorreu 212 vezes, o que corresponde a $27,6 \%$ do corpus e, finalmente, /l/ foi ressilabificada como lateral coronal [l] em onset em 2,55\% dos dados analisados, como elucidado pela tabela 1 que, além do número total de ocorrências por variável, mostra o número de palavras distintas que foram analisadas.

Tabela 1. Realização de /// em coda no PST.

\begin{tabular}{c|c|c|c}
\hline Variável & Palavras & Ocorrências & Percentuais \\
\hline$[\dagger]$ & 137 & 371 & $49,87 \%(371 / 744)$ \\
\hline$[\mathrm{w}]$ & 92 & 142 & $19,09 \%(142 / 744)$ \\
\hline$\varnothing$ & 69 & 212 & $28,49 \%(212 / 744)$ \\
\hline Ressilabificação & 14 & 19 & $2,55 \%(19 / 744)$ \\
\hline Total & 312 & 744 & $100 \%$ \\
\hline
\end{tabular}

Fonte: Elaboração própria

No que diz respeito à tonicidade silábica, observamos que [t], [w], bem como o apagamento da coda, são possíveis em sílabas átonas e tônicas, não constituindo este um fator de bloqueio ou gatilho para os fenômenos. Na tabela 2, apresentamos as ocorrências de cada variável conforme a tonicidade da sílaba que contém a lateral, indicando o percentual das ocorrências de [t], [w] e $\varnothing$ em sílabas tônicas e átonas. 0 total de ocorrências observado é 725 , ao invés de 744 , como na tabela 1, devido ao fato de que as 19 ocorrências em que a lateral é ressilabificada não estão incluídas na tabela 2, bem como nas tabelas 3, 4 e 8.

Tabela 2. Percentual de [t], [w] e $\varnothing$ conforme a tonicidade da sílaba

\begin{tabular}{c|c|c|c|c|c}
\hline \multirow{2}{*}{ Variável } & \multirow{2}{*}{$\begin{array}{c}\text { Total de } \\
\text { ocorrências }\end{array}$} & \multicolumn{2}{|c|}{ Tônicas } & \multicolumn{2}{c}{ Átonas } \\
\cline { 3 - 6 } & Ocorrências & Percentuais & Ocorrências & Percentuais \\
\hline$[\mathrm{t}]$ & 371 & 233 & $62,80 \%(233 / 371)$ & 138 & $37,20 \%(138 / 371)$ \\
\hline$[\mathrm{W}]$ & 142 & 97 & $68,31 \%(97 / 142)$ & 45 & $31,69 \%(45 / 142)$ \\
\hline$\varnothing$ & 212 & 74 & $34,91 \%(74 / 212)$ & 138 & $65,09 \%(138 / 212)$ \\
\hline Totais & 725 & 404 & & 321 & \\
\hline
\end{tabular}

Fonte: Elaboração própria 
Na tabela 2 os percentuais de ocorrência de [t], [w] e $\varnothing$, em sílabas tônicas e átonas, são estabelecidos em relação às ocorrências totais de cada variável: [t] (371); [w] (142) e $\varnothing$ (212). De acordo com tal critério, constatamos que a velarização e a vocalização são favorecidas em sílabas tônicas, uma vez que, do total de ocorrências de [t], 62,8\% ocorreram em tônicas, e, de forma análoga, das ocorrências de [w], 68,31\% foram contatadas em átonas. 0 apagamento, por outro lado, é percentualmente favorecido em sílabas átonas, posto que dentre os apagamentos detectados, 65,09\% ocorreram em átonas.

Considerando, ainda, que trabalhos como o de Callou e Serra (2012) atestam que fenômenos de apagamento e enfraquecimento em coda são mais recorrentes em final de palavra prosódica do que em seu interior, analisamos as variáveis [t], [w] e $\varnothing$ conforme sua posição na palavra morfológica e prosódica. Essa divisão é necessária dado que nem sempre a palavra morfológica coincide com a palavra prosódica. Conforme Vigário (2003), uma palavra prosódica (Pph) é definida pelo acento, isto é, todo elemento com um acento deve estar inserido em uma palavra prosódica. Desse modo, palavras morfológicas como sol (['sot]) Pph e almoço ([ał'mosv]) Pph, por conterem apenas um acento, são interpretadas, também, como uma palavra prosódica enquanto palavras morfológicas como geralmente [,zerat'mẽtı] podem suscitar dúvidas, já que a presença de dois acentos justificam duas palavras prosódicas: (geral) Pph (mente) Pph. No PB e no PE, sufixos como -inh, -zinh, -íssim, -dade e -mente, por exemplo, têm sido analisados como possíveis palavras fonológicas independentes, pois são portadoras de uma proeminência autônoma em relação à sua base (cf. LEE, 1999; MATEUS, 2004; ULRICH; SCHWINDT, 2018). Assumindo que tais sufixos podem, também no PST, serem interpretados como uma palavra prosódica independente, distinguimos as ocorrências de palavras morfológicas e de palavras prosódicas. Os resultados que consideraram a palavra morfológica são demonstrados na tabela 3.

Tabela 3. Variáveis [t], [W] e Ø conforme a posição da sílaba dentro da palavra morfológica

\begin{tabular}{c|c|c|c|c|c}
\hline \multirow{2}{*}{ Variável } & \multirow{2}{*}{$\begin{array}{c}\text { Total de } \\
\text { ocorrências }\end{array}$} & \multicolumn{2}{|c|}{ Fronteira de palavra morfológica } & \multicolumn{2}{c}{ Meio de palavra morfológica } \\
\cline { 3 - 6 } & Ocorrências & Percentuais & Ocorrências & Percentuais \\
\hline$[t]$ & 371 & 221 & $59,57 \%(221 / 371)$ & 150 & $40,43 \%(150 / 371)$ \\
\hline$[\mathrm{w}]$ & 142 & 74 & $52,11 \%(74 / 142)$ & 68 & $47,89 \%(68 / 142)$ \\
\hline$\varnothing$ & 212 & 72 & $33,96 \%(72 / 212)$ & 140 & $66,04 \%(140 / 212)$ \\
\hline Totais & 725 & 367 & & 358 & \\
\hline
\end{tabular}

Fonte: Elaboração própria 
Na tabela 3, examinamos, primeiramente, as ocorrências cuja lateral coincidiam ou não com a borda morfológica da palavra. Ao examinar os percentuais em relação ao total de ocorrências de cada variável, notamos que [t] e [w] são mais comuns em fronteira de palavra morfológica, sendo registrados os respectivos percentuais, 59,57\% e 52,11\%, ao passo que o apagamento ocorreu com maior frequência em meio de palavra morfológica $(66,04 \%)$.

Na tabela 5, por seu turno, apresentamos os resultados que consideraram as fronteiras de palavra prosódica. Nesta tabela, ocorrências de palavras constituídas pelos sufixos -dade e -mente, como geralmente [,zerał'mẽtr] e igualdade [i,g voat'dadI], foram interpretadas como duas palavras prosódicas. Do total de ocorrências da lateral em fronteira de palavra morfológica (367), foram constatadas 41 em palavras morfológicas formadas por duas palavras prosódicas como evidenciado na tabela 4.

Tabela 4. Variáveis [t], [w] e $\varnothing$ em meio de palavra morfológica e em fronteira de palavra prosódica

\begin{tabular}{c|c}
\hline Variável & Ocorrências \\
\hline$[\mathrm{t}]$ & 14 \\
\hline$[\mathrm{W}]$ & 6 \\
\hline$\varnothing$ & 21 \\
\hline Total & 41 \\
\hline
\end{tabular}

Fonte: Elaboração própria

A tabela 5 apresenta o número de ocorrências em fronteira de palavra com o acréscimo dos valores apontados na tabela 4 e, consequentemente, a subtração desses mesmos valores nas ocorrências em meio de palavra. Como pode ser verificado, o meio de palavra fonológica mantém-se como o contexto que mais favoreceu o apagamento $(56,13 \%)$, ao passo que, em fronteira de palavra, [t] $(63,34 \%)$ e [w] $(56,33 \%)$ foram, ainda, mais recorrentes.

Tabela 5. Variáveis [t], [w] e Ø conforme a posição da sílaba dentro da palavra prosódica

\begin{tabular}{c|c|c|c|c|c}
\hline \multirow{2}{*}{ Variável } & \multirow{2}{*}{$\begin{array}{c}\text { Total de } \\
\text { ocorrências }\end{array}$} & \multicolumn{2}{c|}{ Fronteira de palavra fonológica } & \multicolumn{2}{|c}{ Meio de palavra fonológica } \\
\cline { 3 - 6 } & & Ocorrências & Percentuais & Ocorrências & Percentuais \\
\hline$[\dagger]$ & 371 & 235 & $\begin{array}{c}63,34 \% \\
(235 / 371)\end{array}$ & 136 & $36,65 \%(136 / 371)$ \\
\hline$[w]$ & 142 & 80 & $56,33 \%(80 / 142)$ & 62 & $43,66 \%(62 / 142)$ \\
\hline$\varnothing$ & 212 & 93 & $43,86 \%(93 / 212)$ & 119 & $56,13 \%(119 / 212)$ \\
\hline & 725 & & & & \\
\hline
\end{tabular}

Fonte: Elaboração própria 
A partir dos dados percentuais apresentados nas tabelas 3 e 5, verificamos que, embora o apagamento de /I/ em coda seja um processo recorrente no PST, tal fenômeno, nos dados analisados, não é mais produtivo em fronteira de palavra morfológica e/ou prosódica, como postulado para o português brasileiro e europeu (CALLOU; SERRA, 2012; RODRIGUES, 2012). Isto é, no PST, o apagamento da lateral foi mais frequente em meio de palavra, sugerindo, por um lado, que a fronteira de palavra não constitui um domínio favorecedor do fenômeno nesta variedade e, por outro, que mesmo demonstrando a possibilidade de /I/ em coda ser realizado como [t] ou [w], a variedade de São Tomé apresenta traços intrínsecos que não estão, necessariamente, presentes no PB e/ou no $P E^{6}$.

Ao considerar o contexto fônico precedente (CF1), constatamos a realização de [t] diante das sete vogais orais do PST (cf. CHRISTOFOLETTI; ARAUJO, 2018), como indicado na tabela 6. Nesta tabela, o número de ocorrências de [t] é analisado, de modo individual, em relação a cada um dos CF1 [i, e, $\varepsilon, a, 0,0, u]$. Essa abordagem foi adotada para que cada contexto seja avaliado de forma autônoma, neutralizando diferenças decorrentes da distribuição não uniforme das ocorrências nos contextos vocálicos avaliados?

6 A comparação com o trabalho de Callou e Serra (2012), no entanto, deve ser relativizada, posto que as autoras dedicam-se, exclusivamente, à variedade carioca. Ademais, o estudo em questão examina o apagamento de $/ R /$, segmento distinto de $/ \mathrm{I}$, fato que poderia indicar resultados distintos, como o maior percentual da vocalização em relação ao apagamento da lateral.

7 A esse respeito, notamos, por exemplo, que, dentre os dados investigados, palavras cujo CF1 corresponde a [a] equivalem a $61,46 \%$ do total de ocorrências analisadas, fato que poderia conduzir, erroneamente, à interpretação de que tal vogal favoreceria a velarização. 
Tabela 6. Realizações de [t] conforme vogais que correspondem a CF1

\begin{tabular}{c|c|c|c}
\hline Vogal & Ocorrências por vogal & Ocorrências de [t] & Percentuais \\
\hline$[\mathrm{i}]$ & 75 & 28 & $37,33 \%(28 / 75)$ \\
\hline$[\mathrm{e}]$ & 35 & 27 & $77,14 \%(27 / 35)$ \\
\hline$[\varepsilon]$ & 25 & 18 & $72,00 \%(18 / 25)$ \\
\hline$[\mathrm{a}]$ & 457 & 228 & $49,89 \%(228 / 457)$ \\
\hline$[0]$ & 29 & 23 & $79,31 \%(23 / 29)$ \\
\hline$[\mathrm{o}]$ & 52 & 15 & $28,85 \%(15 / 52)$ \\
\hline$[u]$ & 71 & 32 & $45,07 \%(32 / 71)$ \\
\hline TOTAL & 744 & 371 & $49,87 \%(371 / 744)$ \\
\hline$[D O R S A L]$ & 609 & 298 & $48,93 \%(298 / 609)$ \\
{$[a, 0,0, u]$} & 135 & 73 & $54,07 \%(73 / 135)$ \\
\hline$[A N T E R I O R]$ & & &
\end{tabular}

Fonte: Elaboração própria

Observando o ponto de articulação de CF1 na tabela 6, verificamos que dentre as 609 ocorrências das vogais [dorsal], 298, ou seja, 48,93\% das ocorrências foram sucedidas por [t]. Com base nas vogais [anterior], de outro modo, dentre os 135 contextos vocálicos examinados, 73 ocorrências, ou 54,07\% dos dados, foram realizadas como uma lateral velar, indicando que, dentre as vogais, segmentos com o traço [anterior] tendem a favorecer, um pouco mais, a produção de $[t]$.

Distintamente de [t], a forma vocalizada [w] não pôde ser constatada diante de todas as qualidades vocálicas. Nos dados, quando CF1 correspondia a [e] ou [u], não verificamos a realização de [w], como exposto na tabela 7. 
Tabela 7. Realizações de [w] conforme vogais que correspondem a CF1

\begin{tabular}{c|c|c|c}
\hline Vogal & $\begin{array}{c}\text { Ocorrências por } \\
\text { vogal }\end{array}$ & $\begin{array}{c}\text { Ocorrências de } \\
{[\mathbf{w}]}\end{array}$ & Percentuais \\
\hline$[i]$ & 75 & 4 & $5,33 \%(4 / 75)$ \\
\hline$[e]$ & 35 & 0 & $0,00 \%(0 / 35)$ \\
\hline$[\varepsilon]$ & 25 & 6 & $24,00 \%(6 / 25)$ \\
\hline$[a]$ & 457 & 121 & $26,48 \%(121 / 457)$ \\
\hline$[0]$ & 29 & 1 & $3,45 \%(1 / 29)$ \\
\hline$[0]$ & 52 & 10 & $19,23 \%(10 / 52)$ \\
\hline$[u]$ & 71 & 0 & $0,00 \%(0 / 71)$ \\
\hline TOTAL & 744 & 142 & $19,09 \%(142 / 744)$ \\
\hline$[$ DORSAL] & 609 & 132 & $21,67 \%(132 / 609)$ \\
{$[a, 0,0, u]$} & 135 & 10 & $7,41 \%(10 / 135)$ \\
\hline$[$ ANTERIOR] & & &
\end{tabular}

Fonte: Elaboração própria

Ao contrário dos dados produzidos com a lateral velarizada, nos quais o ponto de articulação [anterior] tende a favorecer a realização de [t], na tabela 7, verificamos que a produção de [w] é favorecida por vogais [dorsal] de forma percentualmente mais evidente. Sendo assim, enquanto foram atestadas 132 ocorrências de [w] diante de vogais [dorsal], totalizando 21,67\% (132/609) do total de dados, apenas 7,41\% ou 10 ocorrências de [w] foram contabilizadas na sequência dessas vogais. Essa diferença torna-se ainda mais saliente ao considerarmos apenas as 142 ocorrências nas quais a vocalização pôde ser constatada, uma vez que a realização de [w] foi observada em 92,9\% (132/142) dos dados que continham $[a, 0,0, u]$. De outro modo, somente $7 \%$ (10/142) dos dados em que [ $\varepsilon, \mathrm{e}, \mathrm{i}]$ correspondiam ao CF1 apresentaram vocalização8.

8 Dentre as 142 ocorrências com [w], 132 equivalem a vogais [dorsal] e 10 a vogais [anterior]. Como a vogal mais recorrente do corpus é [a], tal resultado pode ser reflexo da alta produtividade de tal segmento nos dados. O ideal é que tais resultados sejam revistos tendo em vista uma amostra elicitada que padronize o número de segmentos vocálicos analisados. 
No que tange ao apagamento de /// em coda, notamos que, com exceção de $[\varepsilon]$, o fenômeno foi identificado diante de todas as vogais do PST, sendo, em relação ao corpus, mais frequente em vogais [anterior] 36,30\% do que em vogais [dorsal] 26,77\% (cf. tabela $8)^{9}$.

Tabela 8. Apagamento da lateral em coda conforme vogais que correspondem a CF1

\begin{tabular}{c|c|c|c}
\hline Vogal & Ocorrências por vogal & Ocorrências de $\emptyset$ & Percentuais \\
\hline$[i]$ & 75 & 43 & $57,33 \%(43 / 75)$ \\
\hline$[e]$ & 35 & 6 & $17,14 \%(6 / 35)$ \\
\hline$[\varepsilon]$ & 25 & 0 & $0,00 \%(0 / 25)$ \\
\hline$[a]$ & 457 & 92 & $20,13 \%(92 / 457)$ \\
\hline$[0]$ & 29 & 5 & $17,24 \%(5 / 29)$ \\
\hline$[0]$ & 52 & 27 & $51,92 \%(27 / 52)$ \\
\hline$[u]$ & 71 & 39 & $54,93 \%(39 / 71)$ \\
\hline TOTAL & 744 & 212 & $28,49 \%(212 / 744)$ \\
\hline$[$ DORSAL] & & 163 & $26,77 \%(163 / 609)$ \\
{$[a, 0,0, u]$} & 609 & 49 & $36,30 \%(49 / 135)$ \\
\hline$[$ ANTERIOR] & & & \\
{$[\varepsilon, e, i]$} & 135 & & \\
\hline
\end{tabular}

Fonte: Elaboração própria

Os resultados apresentados nas tabelas 6 e 7 indicam que, embora a vogal precedente não corresponda a um contexto segmental determinante para a vocalização, tal fenômeno é favorecido diante de vogais [dorsal]. Essa tendência está de acordo com trabalhos dedicados à análise do fenômeno no português brasileiro (cf. QUEDNAU, 1993; CALLOU; LEITE; MORAES, 1994; BISOL, 1999; TASCA, 1999; MATEUS; D'ANDRADE, 2000) que apontam a relevância deste traço como gatilho de vocalização.

A velarização e a vocalização em PST, desse modo, podem ser explanadas a partir de uma concepção autossegmental de organização dos segmentos (cf. QUEDNAU, 1993; MATEUS; D'ANDRADE, 2000). Baseados nas produções de [t] e [w] no PST, assumimos que

9 Ao considerarmos apenas os 212 dados nos quais o apagamento foi constatado, notamos que esse percentual é maior em vogais [dorsal] (163/212 - 79,6\%) do que em vogais [anterior] (49/212 $-23,1 \%)$ 
a lateral, em posição de onset e coda, a exemplo do PB e do PE, além de estabelecida como [+lateral], [+consoante] e [+soante], tem o ponto de articulação consonantal preenchido como [coronal, +anterior], informação atribuída por regras defaults do português (cf. MATEUS; D'ANDRADE, 2000, p. 141). Enquanto em onset, a lateral mantém tais traços, em coda, tal segmento lateral adquire, ainda, uma articulação secundária, preenchendo o traço [dorsal, + posterior] ao nó vocálico, configuração que resulta na produção de [t] que, por possuir traços articulatórios consonantais e vocálicos, corresponde a uma consoante complexa (QUEDNAU, 1993). Tanto para Quednau (1993), quanto para Mateus e D'Andrade (2000), a velarização de /// é um fenômeno de articulação secundária, sendo necessário, por isso, que na camada de ponto de articulação haja um lugar para os traços de consoante e para os traços de vogal, assim como proposto por Goldsmith (1990). Na figura 4, expomos a geometria de [t], pela qual podemos identificar os traços [coronal], enquanto ponto de articulação consonantal licenciado, e [dorsal] como ponto de articulação vocálico preenchido.

Figura 4. Geometria de [t]

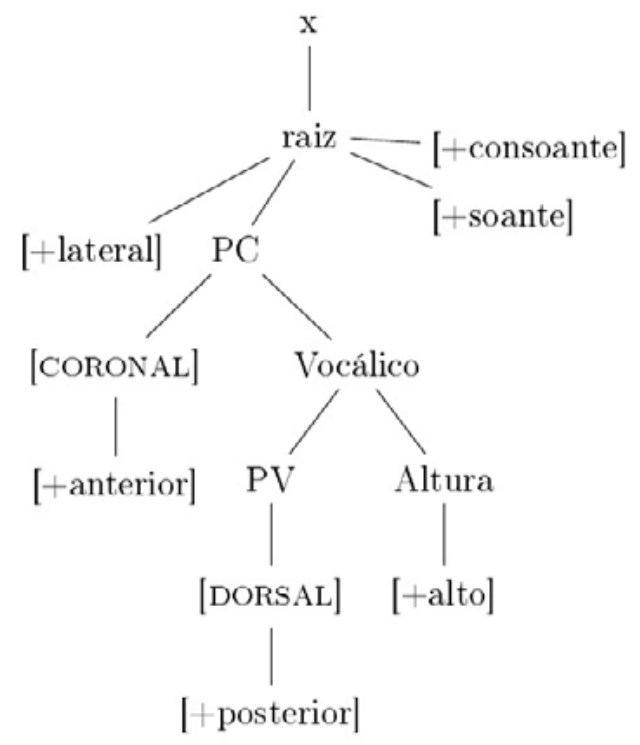

Fonte: Elaboração própria

Enquanto a velarização corresponde a um fenômeno decorrente do preenchimento de traço, caracterizando um processo de fortalecimento da consoante (cf. QUEDNAU, 1993; MATEUS; D'ANDRADE, 2000), a vocalização, no PST, pode ser explicada mediante o desligamento de traço [coronal], e, consequentemente, do traço [+lateral] que confere ao segmento a característica de consoante, configurando um processo de enfraquecimento, como indicado na figura 5. 
Figura 5. Geometria de [w]

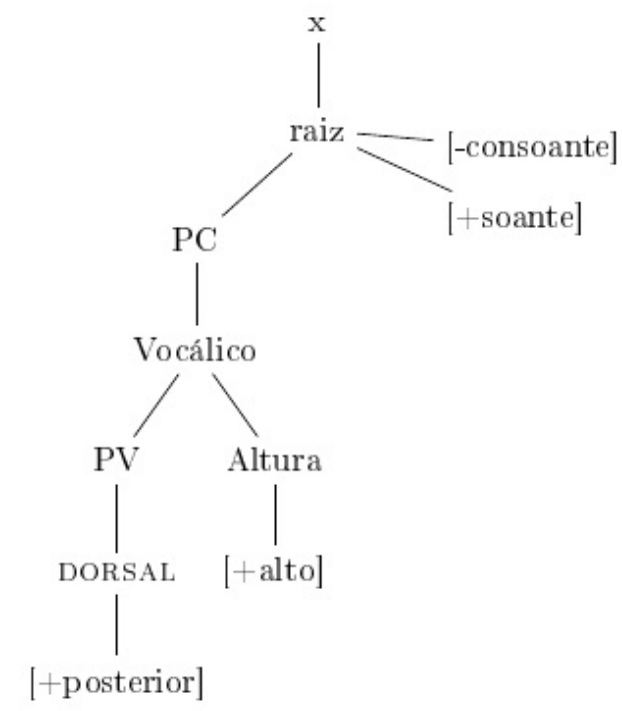

Fonte: Elaboração própria

Ao contrário da representação de [t], o nó consoantal de ponto de articulação não possui especificação, havendo apenas o nó vocálico, o qual é preenchido pelos mesmos traços que a lateral velar. Assim, [w], distintamente de [t], não apresenta uma articulação secundária e pode ser representado por traços vocálicos, demarcando, então, o processo de vocalização (cf. QUEDNAU, 1992; MATEUS; D'ANDRADE, 2000).

No PST, tanto [t] quanto [w] são realizadas em coda, todavia, vogais [dorsal] tendem, percentualmente, a favorecer a vocalização. Assim sendo, suscitamos a hipótese de que o ponto de articulação vocálico pode corroborar, no caso de [a, o, o], o processo de vocalização: sendo tais segmentos vogais [dorsal], inferimos que esse traço reforça o traço [dorsal] vocálico e promove a dissociação do traço consonantal [coronal], resultando em [w]. Vogais anteriores [ $\varepsilon$, e, i] e, portanto, [coronal], de modo distinto, reforçam o ponto de articulação consonantal que também é [coronal], privilegiando a manutenção de tal traço e a consequente produção de $[t]$.

A ressilabificação de /I/, no PST, foi detectada em contexto de sândi consonantal, quando a lateral em coda, além de estar em fronteira de palavra, era seguida por um item lexical iniciado por uma vogal, como indicado em (1). Esses dados foram analisados separadamente dos dados de velarização em fronteira de palavra, pois, com a ressilabificação, a lateral, apesar de estar em fronteira de palavra morfológica, não está em fronteira de palavra prosódica.
a. mi[l]oitocentos
b. manua[l]escolar 
Em casos como (1), a lateral em coda, por ser ressilabificada em onset, é realizada como um segmento [coronal, +anterior], sem ter o ponto de articulação vocálico licenciado. Esse fenômeno, no entanto, não é obrigatório, posto que a vocalização é também possível em fronteira de palavras como indicado em (2).

$$
\text { a. manua[w]escolar }
$$

A possibilidade de ressilabificação ou não de /l/, uma regra pós-lexical na medida em que é aplicada no nível sintático, permite que infiramos que tanto a velarização quanto a vocalização possam corresponder a regras definidas em níveis lexicais anteriores. Assim, se a forma estabelecida for a velar [t], a ressilabificação é possível e pode ocorrer. De outra forma, se o fenômeno aplicado corresponder à vocalização [w], a ressilabificação não ocorre, pois o fone em evidência é desassociado de seus traços consonantais.

No PST, distintamente do PE, variedade na qual a vocalização raramente é reportada na literatura (cf. MATEUS; D'ANDRADE, 2000), e do PB, variedade em que a alternância entre $[t] \sim[w]$ é explicada, sobretudo, mediante variação diatópica (HORA; PEDROSO; CARDOSO, 2010), a oscilação entre a forma velar e vocalizada é constatada na fala de um mesmo indivíduo. De forma a observar se o fator idade pode indicar alguma tendência percentual na implementação de tais processos, as ocorrências de [t] e [w] foram estabelecidas conforme a idade dos informantes (cf. tabela 9).

Tabela 9. Realização de /// em coda no PST conforme a idade dos informantes

\begin{tabular}{c|c|c|c|c}
\hline \multirow{2}{*}{ Variável } & \multicolumn{2}{|c|}{ Até 29 anos } & \multicolumn{2}{c}{30 anos ou mais } \\
\cline { 2 - 5 } & Ocorrências & Percentuais & Ocorrências & Percentuais \\
\hline$[1]$ & 204 & $\begin{array}{c}48,00 \% \\
(204 / 425)\end{array}$ & 167 & $\begin{array}{c}55,67 \% \\
(167 / 300)\end{array}$ \\
\hline$[w]$ & 89 & $\begin{array}{c}20,94 \% \\
(89 / 425)\end{array}$ & 53 & $\begin{array}{c}17,67 \% \\
(53 / 300)\end{array}$ \\
\hline$\varnothing$ & 132 & $\begin{array}{c}31,06 \% \\
(132 / 425)\end{array}$ & 80 & $\begin{array}{c}26,67 \% \\
(80 / 300)\end{array}$ \\
\hline Total & 425 & & 300 & \\
\hline
\end{tabular}

Fonte: Elaboração própria

Em termos percentuais, verificamos que, nos dados, [t] é mais recorrente entre os informantes de 30 anos ou mais, ao passo que [w], de modo contrário, ocorre de forma mais frequente entre os mais jovens. Tais valores sugerem que a importância da faixa 
etária para aplicação do processo de vocalização no PST deve ser investigada de forma mais cautelosa, pois esse fenômeno pode configurar uma mudança em progresso na variedade santomense.

Em suma, observamos que o enfraquecimento de /I/ mediante a vocalização, seu apagamento e mesmo a possibilidade de ressilabificação da lateral em onset, em contexto de sândi consonantal, são resoluções que sugerem a busca por um padrão CV, assim como apontado na literatura para o PB (cf. BRANDÃO et al., 2003). Esse fato é reforçado por estudos que se dedicam à análise do rótico em coda no PST (cf. BOUCHARD, 2017; BRANDÃO et al., 2017) e atestam o frequente apagamento desse segmento. Brandão et al. (2017), por exemplo, indicam que, em posição de coda final, o rótico foi elidido em $44,7 \%$ dos dados investigados, o que pode ser explanado, conforme os autores, como uma tendência, constatada em outras línguas, ao padrão silábico CV (cf. BRANDÃO et al., $2017)^{10}$.

Mesmo diante da aproximação com a variedade brasileira do português, promovida pela produtividade da vocalização de ///, observamos que o fenômeno da vocalização é implementado de forma distinta, já que diversamente do PB, variedade em que esse fenômeno é registrado, de modo comum, como um processo de caráter diatópico (cf. CÂMARA JR., 1970; MATEUS; D'ANDRADE, 2000), no PST a oscilação entre [t] [w] foi verificada, recorrentemente, na fala de um mesmo falante. Logo, notamos que o PST afasta-se da norma de prestígio de STP, o PE, variedade difundida pelo meio escolar, aproxima-se do PB, porém, ainda assim, revela traços intrínsecos.

Este artigo apresentou, de maneira ampla e preliminar, o quadro geral da distribuição de /I/ em coda no PST. Cabe, em trabalhos futuros, averiguar as tendências percentuais levantadas tendo em vista modelos estatísticos que possam atestar a relevância de fatores linguísticos e externos para ocorrência da velarização, vocalização e apagamento da lateral. É interessante, ainda, que os resultados aqui apresentados sejam examinados a partir de dados de fala controlada e semiespontânea, os quais permitam isolar contextos que possam favorecer ou limiar a realização de tais processos. Por fim, de modo a caracterizar a sílaba no PST, constituinte linguístico pouco descrito nessa variedade, é necessária a análise da distribuição de outros segmentos licenciados em coda, bem como a verificação da possibilidade de implementação de fenômenos de enfraquecimento, apagamento e ressilabificação identificados nesse domínio.

10 Brandão et al. (2017) descartam, assim, a possibilidade do apagamento do rótico ser resultado do contato linguístico entre o PST e línguas locais, posto que esta é uma tendência de caráter universal. Em relação à lateral, tampouco há evidências que o santome esteja influenciando no processo de vocalização e/ou apagamento da coda /l/, pois além de a lateral não ser licenciada em coda nessa língua, o processo de vocalização não é reportado na literatura (cf. BANDEIRA, 2017). 


\section{Considerações finais}

A exemplo do PB, a coda /I/, no PST, pode ser realizada, por um mesmo falante, como uma lateral velar [t] (49,87\%), um glide [w] (19,09\%) ou mesmo ser apagada. No geral, a velarização é mais recorrente diante de segmentos vocálicos [anterior], ao passo que a vocalização éum processo constatado, principalmente, diante devogais [dorsal], sugerindo a relevância desse traço para a realização de tal fenômeno na variedade santomense. Ademais, o apagamento de /// também foi recorrente nos dados investigados, sendo identificado em $28,49 \%$ dos dados e configurando uma estratégia de resolução de coda ainda mais produtiva do que a vocalização. Por fim, /// foi ressilabificado, em onset, em 2,55\% do corpus, caracterizando-se como um processo comum, porém não obrigatório, e sendo implementado quando a lateral estava em fronteira de palavra e o item lexical seguinte era iniciado por uma vogal. O PST pode, assim, ser caracterizado como uma variedade da língua portuguesa com traços compartilhados com outras variedades do português, como o PB e o PE, contudo, detendo traços intrínsecos.

\section{REFERÊNCIAS}

ARAUJO, G.; BALDUINO, A. M. Nasalização Vocálica no Português Urbano de São Tomé e Príncipe. Diacrítica, v. 33, n. 2, p. 41-68, 2019.

BALDUINO, A. M. A nasalidade vocálica no português falado em São Tomé e Príncipe. 2018. Dissertação (Mestrado em Letras) - Faculdade de Filosofia, Letras e Ciências Humanas, Universidade de São Paulo, São Paulo, 2018.

BALDUINO, A. M. Apagamento de /R/ e /S/ em coda no Português Principense. Papia, São Paulo, v. 29, n. 1, p. 25-39, 2019.

BISOL, L. A sílaba e seus constituintes. In: NEVES, M. H. de M. (org.) Gramática do Português culto falado: novos estudos. Campinas: Editora da Unicamp, v. 7, p. 701-742, 1999.

BOERSMA, P.; WEENINK, D. Praat: doing phonetics by computer (Version 5.3.82) Computer Program, 2016. Disponível em: http://www. praat.org. Acesso em: 20 jan. 2018.

BOUCHARD, M. Linguistic Variation and change in the Portuguese of São Tomé. Tese (Doutorado em Filosofia) - Departamento de Linguística, New York University, New York, 2017. 
BRAGA, G. A prosódia do português de São Tomé: a entoação do contorno neutro. 2018. Dissertação (Mestrado em Filologia e Língua Portuguesa) - Faculdade de Filosofia, Letras e Ciências Humanas, Universidade de São Paulo, São Paulo, 2018.

BRANDÃO, S. F.; MOTA, M. A.; CUNHA, C. S. Um estudo contrastivo entre o português europeu e o português do Brasil: o -R final de vocábulo. In: BRANDÃO, S.; MOTA, M. A. (org.). Análise contrastiva de variedades do português. Rio de Janeiro: In-Fólio, 2003.

BRANDÃO, S. F.; PESSANHA, D.; PONTES, S.; CORRÊA, M. Róticos na variedade urbana do português de São Tomé. PAPIA, v. 27, n. 2, p. 293-315, jul./dez. 2017.

BROD, L. E. A lateral nos falares orianopolitano (PB) e portuense (PE): casos de gradiência fônica. 2014. Tese (Doutorado em Linguística) - Centro de Comunicação e Expressão, Universidade Federal de Santa Catarina, Florianópolis, 2014.

CALLOU, D.; SERRA, C. Variação do rótico e estrutura prosódica. Revista do GELNE, v. 14, n. esp., p. 41-58, 2012.

CALLOU, D.; LEITE, Y.; MORAES, J. Variação e diferenciação dialetal: a pronúncia do /r/ no português do Brasil. In: KOCH, I. G. V. Gramática do Português Falado. Campinas: Editora da Unicamp/FAPESP, 1994. p. 465-493.

CÂMARA JR, J. M. Estrutura da Língua Portuguesa. Petrópolis: Vozes, 1970.

CHRISTOFOLETTI, A. Ditongos no português de São Tomé e Príncipe. 2013. Dissertação (Mestrado em Letras) - Faculdade de Filosofia, Letras e Ciências Humanas, Universidade de São Paulo, São Paulo, 2013.

CHRISTOFOLETTI, A.; ARAUJO, G. Vogais e Ditongos no Português Vernacular de São Tomé e Príncipe. In: OLIVEIRA, M. S. D.; ARAUJO, G. A. (org.). O Português na África Atlântica. São Paulo: Humanitas/Fapesp, 2018. p. 258-296.

FIGUEIREDO, C. A concordância plural variável no sintagma nominal do português reestruturado da comunidade de Almoxarife, São Tomé. 2010. Tese (Doutorado em Linguística) - Faculdade de Ciências Sociais e Humanas, Universidade de Macau, Macau, 2010.

GOLDSMITH, J. A. Syllable Structure. In: GOLDSMITH, J. Autosegmental and metrical phonology. Nova Jersey: Wiley-Blackwell Publishing, 1990. p. 103-140. 
GONÇALVES, R. Propriedade de Subcategorização verbal no português de S. Tomé. 2010. Dissertação (Mestrado em Linguística) - Faculdade de Letras, Universidade de Lisboa, Lisboa, 2010.

HORA, D.; PEDROSA, J.; CARDOSO, W. Status da consoante pós-vocálica no português brasileiro: coda ou onset com núcleo não preenchido foneticamente? Letras de Hoje, Porto Alegre, v. 45, n. 1, p. 71-79, 2010.

INSTITUTO NACIONAL DE ESTATÍSTICA (INE). 2011. São Tomé e Príncipe em Números. São Tomé: 2001. Disponível em: http://http://www.ine.st/2012.html. Acesso em: 12 fev. 2020.

LADEFOGED, P.; JOHNSON, K. A Course in Phonetics. Canadá: Wadsworth, 2011.

LEE, S. H. Sobre a formação de diminutivo do português brasileiro. Revista de Estudos da Linguagem, v. 8, n. 1, p. 113-124, 1999.

LEE, S. H. Interface Fonologia-Morfologia: Diminutivos no PB. Revista Diadorim, n. esp., p. 113-125, 2013.

MATEUS, M. H. Estudando a melodia da fala: traços prosódicos e constituintes prosódicos. In: Encontro sobre o Ensino das Línguas e a Linguística APL e ESE de Setúbal, Setúbal, Portugal, 2004.

MATEUS, M. H.; D'ANDRADE, E. The Phonology of Portuguese. Oxford: Oxford linguistics, 2000.

MATEUS, M. H.; RODRIGUES, C. A vibrante em coda no Português Europeu. Actas do XIX Encontro, 2004.

QUEDNAU, L. R. A lateral pós-vocálica no português gaúcho: análise variacionista e representação não-linear. 1993. Dissertação (Mestrado em Letras) - Instituto de Letras, Universidade Federal do Rio Grande do Sul, Porto Alegre, 1993.

RODRIGUES, M. C. Todas as codas são frágeis em português europeu? Revista LinguíStica / Revista do Programa de Pós-Graduação em Linguística, Universidade Federal do Rio de Janeiro, Rio de Janeiro, v. 8, n. 1, p. 211-227, 2012. 
TASCA, M. A lateral em coda silábica no sul do Brasil. 2011. Tese (Doutorado) - Pontifícia Universidade Católica do Rio Grande do Sul, Porto Alegre, 2011.

VIGÁRIO, M. The Prosodic Word in European Portuguese. Berlin-New-York: Mouton de Gruyter, 2003.

ULRICH, C. W.; SCHWINDT, L. C. O status morfoprosódico dos sufixos -inho/-zinho, -mente e -íssimo no português brasileiro. D.E.L.T.A, São Paulo, v. 34, n. 2, p. 769-788, 2018. 